\title{
Spatiotemporal Variations of Landscape Ecological Risks in a Resource-Based City under Transformation
}

\author{
Dong Wang ${ }^{1,2}$, Xiang $\mathrm{Ji}^{1, *}$, Cheng $\mathrm{Li}^{3}$ and Yaxi Gong ${ }^{1}$ \\ 1 School of Mechanics and Civil Engineering, China University of Mining and Technology, \\ Xuzhou 221000, China; dong_w1124@163.com (D.W.); gongyaxi@cumt.edu.cn (Y.G.) \\ 2 Jiangsu Collaborative Innovation Center for Building Energy Saving and Construction Technology, \\ Jiangsu Vocational Institute of Architectural Technology, Xuzhou 221000, China \\ 3 School of Architecture \& Design, China University of Mining and Technology, Xuzhou 221000, China; \\ cheng.li@cumt.edu.cn \\ * Correspondence: jixiang0615@yeah.net
}

Citation: Wang, D.; Ji, X.; Li, C.;

Gong, Y. Spatiotemporal Variations of Landscape Ecological Risks in a Resource-Based City under Transformation. Sustainability 2021,

13, 5297. https://doi.org/

$10.3390 /$ su13095297

Academic Editor: Leslie A. Duram

Received: 8 April 2021

Accepted: 5 May 2021

Published: 10 May 2021

Publisher's Note: MDPI stays neutral with regard to jurisdictional claims in published maps and institutional affiliations.

Copyright: (c) 2021 by the authors. Licensee MDPI, Basel, Switzerland. This article is an open access article distributed under the terms and conditions of the Creative Commons Attribution (CC BY) license (https:// creativecommons.org/licenses/by/ $4.0 /)$.

\begin{abstract}
The development of traditional resource-based cities requires drastic changes owing to the exhaustion of resources. During this transformation, the ecological environment of resource-based cities is threatened because of resource exploitation, in addition to the ecological risks caused by urban expansion. However, there is currently a lack of research on the evolution of ecological dangers in cities during this transformational period. Therefore, conducting relevant studies is essential to establishing a mechanism to mitigate these dangers. The present study analyzed Xuzhou, a typical resource-based city in China, as a case study. The main objective was to consider the dynamic changes in land use and ecological risks during the transformation of this resource-based city. The land-use changes in Xuzhou in 2000, 2010, and 2020 were analyzed, using the Markov model and landscape-pattern indices, allowing an ecological risk-assessment model of land-use changes to be constructed. Additionally, the spatial heterogeneity of ecological risks was evaluated by using spatial autocorrelation. The results showed that urban expansion influenced land use in Xuzhou significantly. Owing to the rapid urban expansion, the area of extremely high-risk regions increased significantly in 2010. Furthermore, the subsidence areas caused by mining had profound impacts on the region's ecology, and early interventions for ecological restoration are needed to prevent further deterioration. During the transformation, Xuzhou's overall ecological risks reduced gradually, which was conducive to its transition into an ecological city.
\end{abstract}

Keywords: ecological risk assessment; resource-based city; land-use changes; ecological restoration

\section{Introduction}

The health of ecosystems is key to human sustainable development [1]. Ecosystems respond to disturbances caused by human activities but are also the foundation that supports human activities [2,3]. Compared with the natural evolution of ecosystems, ecosystem responses to human activities are more direct and severe: human activities can modulate ecological risk directly in a short period [4,5]. Ecological risk refers to the possibility of external pressures causing adverse effects on an ecosystem [6-9]. Ecological risk variation is a complicated systematic process influenced by various aspects, such as nature, society, and the economy. These elements interact on different and temporal scales, resulting in the complexity of, and uncertainty about, the evolution of ecological risk [10]. Therefore, establishing a scientifically based assessment system for ecological risk and analyzing the dynamics of ecological risk are both conducive to establishing a warning system for ecological risk. This would enable the more accurate and efficient control of ecological risk.

Ecological risk assessment originates from studies on ecotoxicology [11]. Previous studies have evaluated the influences of individual chemical pollutants on the environment 
and human health. This has enabled the analysis of the formation and diffusion of chemical pollution and regional ecosystem responses, since the end of the 1980s, accompanied by a significant expansion of research objectives, content, and methods. Ecological risk assessment has shifted focus from studies on toxicological risk to the assessment of ecological risk on different scales $[12,13]$. Assessment of ecological risk in landscapes is an important branch of ecological risk assessment [14]. The key to landscape ecological risk assessment lies in the ecological risk caused by changing land-use patterns, as it aims to predict the effects of changes in landscape patterns on landscape processes $[15,16]$. Compared with traditional ecological risk assessment, the assessment of ecological risk on the landscape scale pays particular attention to spatial heterogeneity. To date, landscape ecological risks associated with forests [17-19], river basins [20-22], coastal regions [23-25], arid deserts [15], national parks [26], cities [27-29], and mining areas [30-32] have been studied.

The key to ecological risk assessment in landscapes lies in establishing an evaluation system and selecting suitable indices. Two methods are widely applied at present. The first is an ecological risk evaluation system based on the "pressure-receptor-response" model and failure mechanism [25]. This method is usually used to evaluate the ecological risk of a specific pressure or interference source. The second takes a deviation from the optimal pattern as the risk source and evaluates the ecological effects [31-33]. In this method, the whole system is viewed as the receptor, and the ecological risk is usually evaluated in terms of ecological variation within the entire region, and then using landscape pattern indices to portray the research object landscape $[34,35]$. Research using this second method often uses landscape pattern indices in the study area as elements [16], establishing ecological disturbance and ecological vulnerability through weight assignments. Using these indices, the threat posed to various landscape elements in the study areas is determined. Moreover, the ecological risk in the study area is assessed by the composition of and threat to various landscape elements $[32,33]$. Various landscape pattern indices and weighting methods are chosen to consider different research objects. Common landscape pattern indices include the degree of fragmentation, degree of dispersion, degree of dominance [36,37], dimension, and shape indices [32]. Common weighting methods include artificial assignment [25], normalization [36], the entropy weight method, and the analytic hierarchy process (AHP) [32]. To date, these methods have generally been applied to river basins [37] and cities [32,38]. Firstly, the research object is divided into landscape units, using a grid. Then the ecological risk value of the landscape units is calculated according to the landscape pattern index of different land-use types in the landscape unit. Finally, the ecological risk diagram is developed through the Kriging interpolation [39]. Meanwhile, the variation in spatiotemporal relationships between land-use changes and ecological risks are statistically analyzed to determine areas of different ecological risk levels [32,33]. The second method was chosen in the present study based on previous studies, according to the research objective and the ecological characteristics of the research object.

Resource-based cities are types of cities that take the mining and processing of natural resources, such as local minerals and forests, as their leading industries. The production and development of cities are closely related to resource extraction, the economic structure is simple, and resource extraction accounts for a relatively high proportion of urban output value. According to the sequence of resource exploitation and city formation, there are two modes for the formation of resource-based cities. One is the "mining first and city later" mode; that is, the city emerges entirely because of resource mining. The other is the "city first and mine later"; that is, there are cities before the development of resources, and the development of resources accelerates the development of the city. Compared with other types of cities, the ecological environment of resource-based cities is severely damaged [30]. After resource exhaustion, resource-based cities face city transition problems, and the damaged ecological environment becomes a heavy burden that discourages urban development [32,40]. Therefore, resource-based cities have become a research hotspot for ecological restoration [40,41]. Some studies have focused on ecological risk assessment for resource-based cities. These have mainly focused on analyzing urban ecological risks due 
to industrial pollution, such as the effects of excessive heavy metals and acid wastewater in mining mountains [42]. Some previous studies have considered the landscape ecological risks of resource-based cities at different stages [31,32]. However, no studies have discussed the transformation period of resource-based cities. In this period, economic structures can become more diversified, and development during urban transformation can result in multiple pressures on the ecological environment. Therefore, studying the ecological environment is essential to establish a risk-warning mechanism during the transformation phase of a resource-based city.

As a traditional resource-based city, Xuzhou has gradually been experiencing resource exhaustion since the 21st century began and has entered the transformation period. There was increased ecological and environmental restoration in Xuzhou during this rapid development, culminating in the city being awarded the UN-Habitat Award in 2018. Xuzhou was ranked 33rd in the GDP ranking of Chinese cities in the same year. Xuzhou has achieved remarkable results in industrial economic transformation and ecological environmental protection. Xuzhou was chosen in the present study, using landscape ecology methods to explore the ecological risks caused by land-use changes, without considering the changes in ecological risks caused by environmental pollution, natural disasters, and other factors. Assuming that land-use types belonging to the same category have the same impact on ecological risks, the secondary classification of land-use types was not taken into consideration. This study considered land use during the transformation period of this resource-based city and the evolution of landscape ecological risks. The land-use changes were demonstrated and assessed by using the Markov model and landscape pattern indices. An ecological risk index system was set up on this basis, and the ecological risk during Xuzhou's transformation period was evaluated. Furthermore, statistical analysis of the areas that had converted between different risk levels was performed. Finally, the spatial correlation of ecological risks in various years was calculated.

\section{Study Area and Data Source}

\subsection{Study Area}

Jiangsu Province $\left(30^{\circ} 46^{\prime}-35^{\circ} 9^{\prime} \mathrm{N}, 116^{\circ} 21^{\prime}-121^{\circ} 58^{\prime} \mathrm{E}\right)$ is located in Eastern China, and Xuzhou $\left(33^{\circ} 43^{\prime \prime} \sim 34^{\circ} 58^{\prime} \mathrm{N}, 116^{\circ} 22^{\prime} \sim 118^{\circ} 40^{\prime} \mathrm{E}\right)$ is in the northwest region of Jiangsu Province (Figure 1). The total area of Xuzhou is $11,202 \mathrm{~km}^{2}$, including a city area of $3038 \mathrm{~km}^{2}$. The city area covers five administrative districts, namely Gulou, Quanshan, Yunlong, Tongshan, and Jiawang. Five counties (cities) include Pizhou, Xinyi, Fengxian, Peixian, and Suining.
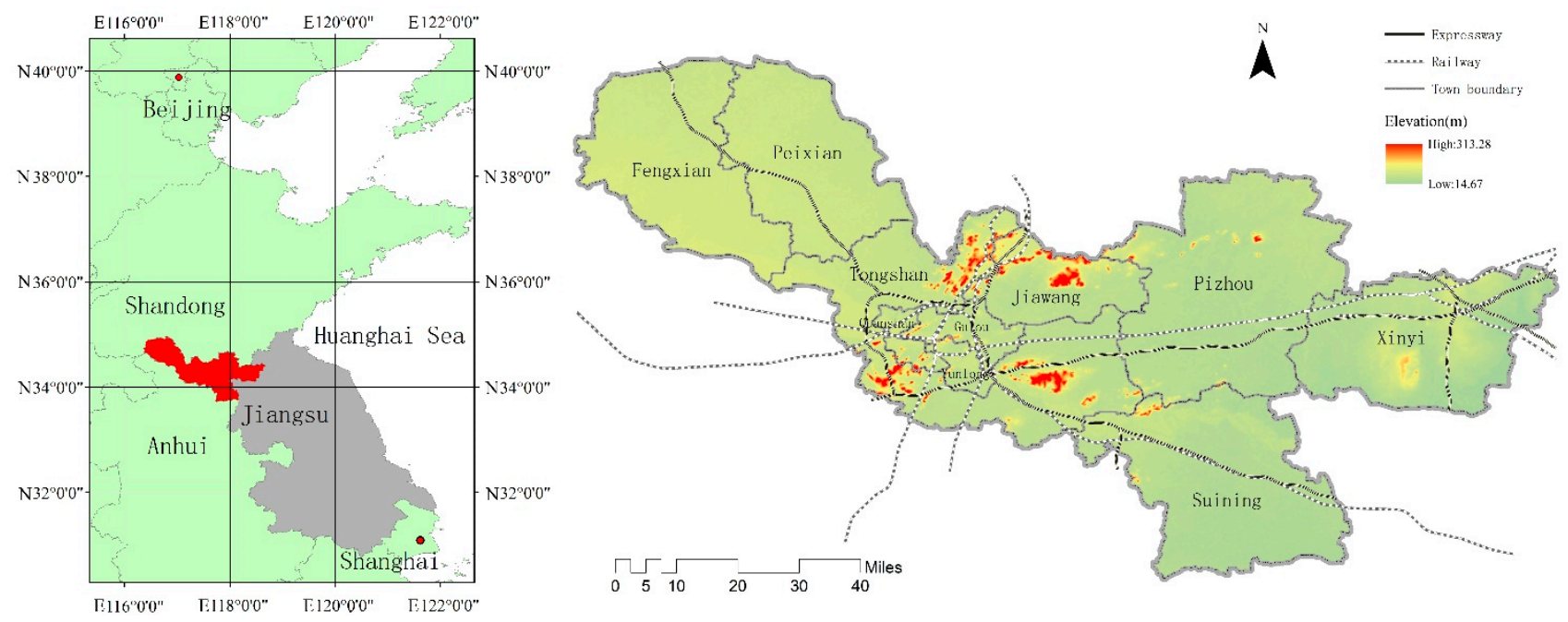

Figure 1. Location of Xuzhou in China.

Xuzhou is an interlacing zone of flood plains, hills, and lake depressions. The flat area accounts for approximately $90 \%$ of the city area, with the altitude ranging from 30 
to $50 \mathrm{~m}$. Hills and mountains account for about $9.4 \%$ of the city area, with an average altitude of approximately $200 \mathrm{~m}$. Xuzhou belongs to a temperate monsoon climate with four distinctive seasons but is not hot in summer or cold in winter.

Around 2005, Xuzhou coal mines were declared exhausted, and many began to close one after another. Xuzhou entered the phase of development transformation. Coal mining had led to the frequent occurrence of secondary geological disasters, among which largescale mined-out collapses were particularly typical. The coal-mining subsidence areas that have had the greatest impact on the development of Xuzhou's urban area are mainly concentrated in the Jiuli Lake area in the northwest of Quanshan and the Pan'an Lake area in the southwest of Jiawang. Simultaneously, the urban construction of Xuzhou was quickly accelerated, and urban expansion was significant, with the urbanization rate increasing from $25.78 \%$ in 2000 to $61.18 \%$ in 2019 . Under the action of multiple factors, land use has changed significantly, and the influence of these changes on the landscape pattern is increasing [43].

\subsection{Data Source}

This study was mainly based on data from administrative maps, land-use maps, and the Xuzhou statistical yearbook. Land-use maps were formulated by Landsat ETM and TM images collected by the United States Geological Survey (USGS) in 2000, 2010, and 2020. The image resolution was $30 \mathrm{~m}$, and the image data were initially classified and preprocessed using ENVI 5.2 [44]. Subsequently, these were compared to high-resolution satellite maps for post-processing of the supervised classification results. From previous studies and China's land-use classification standards, landscapes in Xuzhou were defined as forest, grassland, cultivated land, construction land, water, and unused land (Table 1, Figure 2). The above datasets were collected from the Geospatial Data Cloud (http:/ / www. gscloud.cn/, accessed on 4 May 2021) provided by the Chinese Academy of Sciences and BIGEMAP software.

Table 1. Classification of land use of Xuzhou.

\begin{tabular}{ccc}
\hline Code & Land-Use Type & Details \\
\hline 1 & Cultivated land & Irrigated land and paddy field. \\
\hline 2 & Forest & Wildwood mainly in hilly areas of the prohibition of development, plantation mainly on \\
the plain, and shrubs.
\end{tabular}

\subsection{Sampling Method}

Appropriate landscape units for landscape ecology are a prerequisite for calculating ecological risk and performing spatial statistical analyses. To better represent the spatial distribution of ecological risks, the sampling unit area was set as $2-5$ times the size of an average plaque area according to the even spacing mesh sampling approach of previous studies [45]. According to the calculated results, $2 \times 2 \mathrm{~km}$ was the optimal grid size, resulting in 3065 sampling units (Figure 3). The center points of sampling units were used for spatial interpolation of the ecological risk index. In this way, a quantitative description of the spatial distribution and variation in landscape ecological risks could be undertaken. 


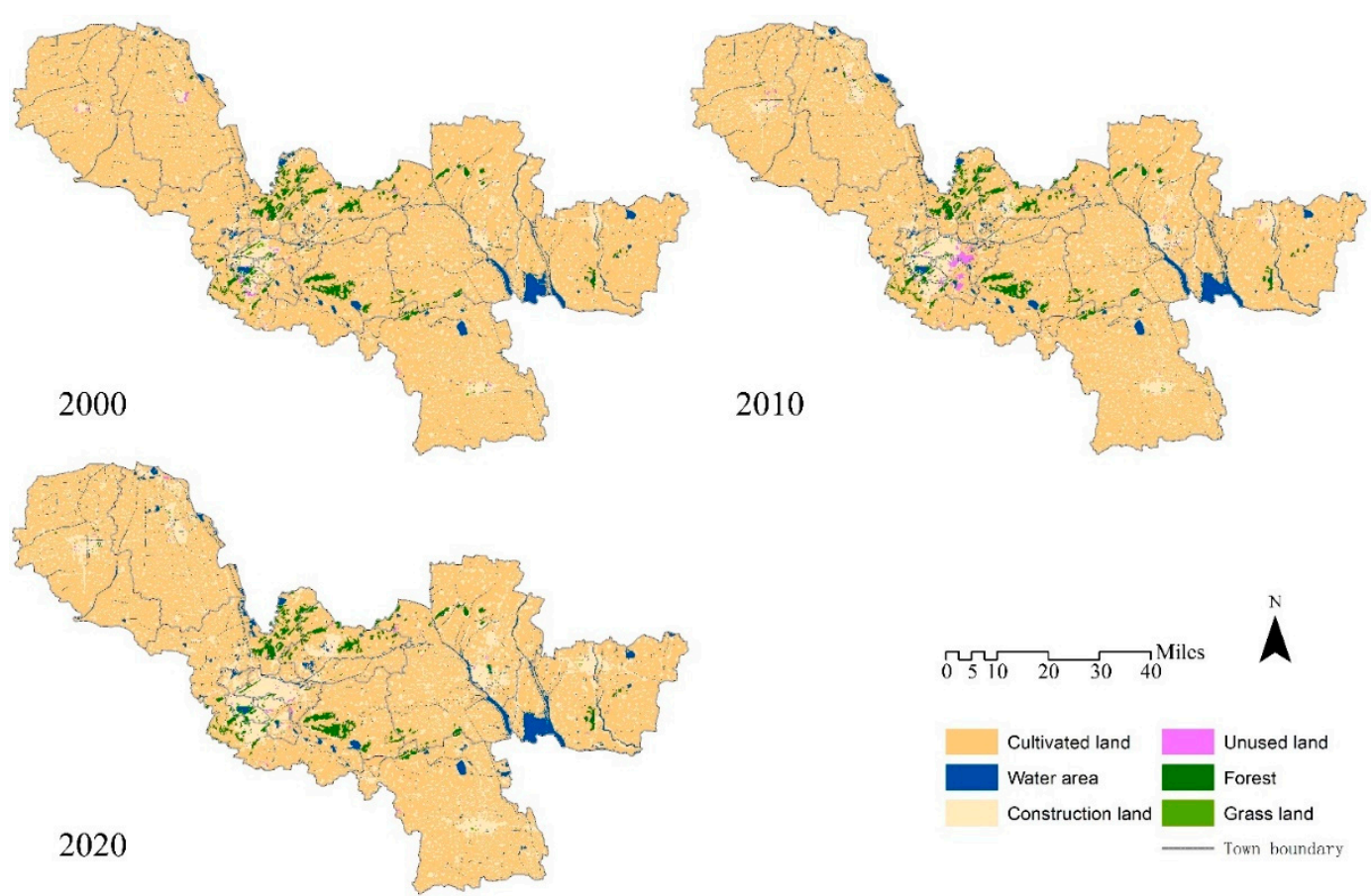

Figure 2. Land-use distribution in Xuzhou from 2000 to 2020.

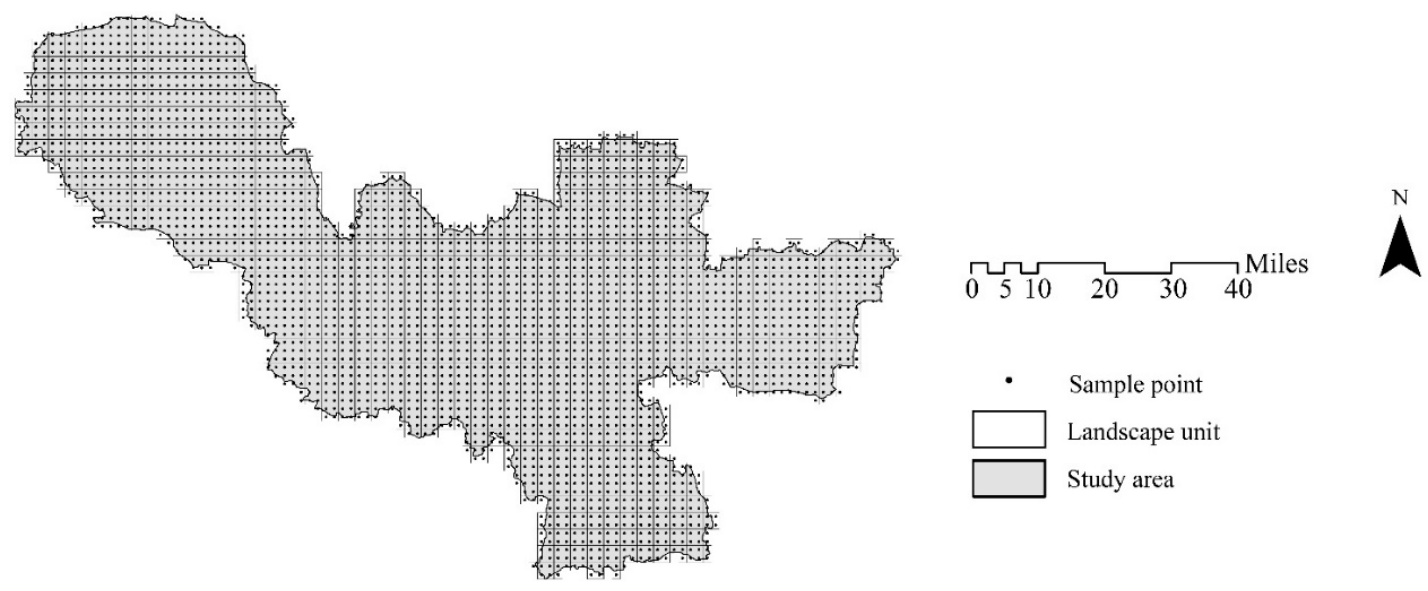

Figure 3. Division of the landscape unit.

\section{Methodology}

\subsection{Land-Use Dynamic Change}

The land-use conversion in this study was evaluated, using the Markov transfer matrix [46]. During the transitional period, as a densely populated district, the land-use intensity in Xuzhou was very high. The land-use intensity between 2000 and 2020 was analyzed according to the land-transfer situation (Equation (1)). Statistical analyses of changes between different land-use types were performed, using Arc GIS 10.2. 


$$
S_{i j}=\left\{\begin{array}{cccccc}
S_{11} & S_{12} & & \ldots & & S_{1 m} \\
S_{21} & S_{22} & & \ldots & & S_{2 m} \\
& & \ddots & & & \\
\vdots & \vdots & & S_{i i} & & \vdots \\
& & & & \ddots & \\
S_{m 1} & S_{m 2} & & \ldots & & S_{m m}
\end{array}\right\}
$$

where $S_{i j}$ is an area that has changed from land-use $i$ to $j$ between two-time points, $S_{i i}$ is an area that has retained land use $i$ between two-time points, and $m$ is the number of land-use types.

\subsection{Landscape Ecological Risk Assessment Model}

\subsubsection{Landscape Ecological Risk Index}

The degree of risk for landscape units was quantified by establishing ecological risk indices. The ecological risk index of a landscape unit was determined by its landscape composition and threat. The threat to the $i$ th land-use type was calculated as a function of the landscape disturbance index $\left(E_{i}\right)$ and landscape fragility index $\left(F_{i}\right)$. The ecological risk index of a landscape unit could then be calculated by summing the result of multiplying the threat and composition of each land-use type in the landscape unit, according to Equation (2):

$$
E R I_{k}=\sum_{i=1}^{n} \frac{A_{k i}}{A_{k}}\left(E_{i} \times F_{i}\right)
$$

where $E R I_{k}$ is the landscape ecological risk index of the $k$ th landscape unit, $A_{k i}$ is the area of the $i$ th land use in the $k$ th landscape unit, $A_{k}$ is the total area of the $k$ th landscape unit, and $n$ is the number of land-use types.

\subsubsection{Landscape Disturbance Index $\left(E_{i}\right)$}

Urban construction and human production activities can influence the land-use composition of landscape units and their associated threats, and therefore the overall landscape ecology of a region. Hence, influences on ecological landscapes and their dynamics can be effectively reflected by comparing the spatial evolution of ERI values over time. Landscape pattern indices representing different aspects of landscape ecology were chosen to establish the landscape disturbance index in Xuzhou due to land-use characteristics.

The landscape disturbance index represents the resistance of landscape patterns to external disturbances. Based on previous studies, the landscape disturbance index $\left(E_{i}\right)$ in the present study was calculated from the fragmentation index $\left(C_{i}\right)$, dispersion index $\left(S_{i}\right)$, dominance index $\left(D o_{i}\right)$, reciprocal of $P A F R A C_{i}$, and the normalized shape index $\left(N_{i}\right)$, as shown in Table 2 [32]. $C_{i}$ represents the degree to which the landscape is divided and is often used to describe the degree of fragmentation of the ecosystem after disturbances, an important cause of decreased biodiversity. $S_{i}$ refers to the degree of dispersion of the spatial distribution of landscape pattern patches. The higher its value, the greater the degree of dispersion of landscape pattern. It can reflect the higher the frequency of conversion between different landscape patterns. $D o_{i}$ represents the advantage of a land-use type in the whole region and reflects the error between landscape diversity and maximum diversity. All of these indices can be used to measure the resistance of the spatial structure of a land-use type to external disturbances. PAFRAC $i$ describes the complexity and stability of the plaque shape at the landscape pattern level, with values ranging from 1 to 2 . When the value of $P A F R A C_{i}$ approaches 1 , the plaque shape is more straightforward and the disturbance is more pronounced. $N_{i}$ describes the landscape shape index of a landscape type after normalization. The higher the value, the smaller the area of the landscape unit and the larger the area of the edge area. Its external disturbance is more easily influences the landscape ecological process. 
Table 2. Indices of landscape disturbance.

\begin{tabular}{|c|c|c|}
\hline Index & Equation & Expression \\
\hline$C_{i}$ & $C_{i}=n_{i} / A_{i}$ & $\begin{array}{l}n_{i} \text { is the patch number of landscape } i \\
\quad A_{i} \text { is the total area of landscape } i .\end{array}$ \\
\hline$S_{i}$ & $S_{i}=A \times \sqrt{n_{i} / A} / 2 A_{i}$ & A is the total area of landscape. \\
\hline$D o_{i}$ & $D o_{i}=\left(Q_{i}+M_{i}\right) / 4+L_{i} / 2$ & $\begin{array}{c}Q_{i} \text { is the number of landscape units with the patch } i \text { divided by } \\
\text { the total number of landscape units; } \\
M_{i} \text { is the number of patch of landscape } i \text { divided by the total } \\
\text { number of patches in the landscape units; } \\
L_{i} \text { is the area of landscape } i \text { divided by the total area of } \\
\text { landscape units. }\end{array}$ \\
\hline$R P_{i}$ & $\begin{array}{c}R P_{i}=1 / \text { PAFRAC } C_{i} P A F R A C= \\
\frac{\left[n_{i} \sum_{j=1}^{n}\left(\ln p_{i j} \times \ln a_{i j}\right)\right]-\left[\left(\sum_{j=1}^{n} \ln p_{i j}\right) \times\left(\sum_{j=1}^{n} \ln a_{i j}\right)\right]}{\left(a \sum_{j=1}^{n} P_{i j}^{2}\right)-\left(\sum_{j=1}^{n} \ln P_{i j}\right)}\end{array}$ & $\begin{array}{l}a_{i j} \text { is the area of patch } i j \\
P_{i j} \text { equals the perimeter of patch } i j\end{array}$ \\
\hline$N_{i}$ & $N_{i}=\left(e_{i}-\right.$ mine $\left._{i}\right) /\left(\operatorname{maxe}_{i}-\right.$ mine $\left._{i}\right)$ & $\begin{array}{l}e_{i} \text { equals the perimeter of landscape } i \\
\text { mine }_{i} \text { equals the minimum perimeter of landscape } i \\
\text { maxe }_{i} \text { equals the maximum perimeter of landscape } i \text {. }\end{array}$ \\
\hline$E_{i}$ & $E_{i}=a C_{i}+b S_{i}+c D o_{i}+d P R_{i}+e N_{i}$ & $\begin{array}{l}a, b, c, d \text {, and } e \text { represent the weights of } C_{i}, S_{i}, D o_{i}, R P_{i} \text {, and } N_{i} ; \\
\qquad a+b+c+d+e=1 .\end{array}$ \\
\hline
\end{tabular}

In the present study, weights were allocated by the entropy evaluation method according to landscape indices in three stages. The entropy evaluation method is a relatively objective and effective method to calculate the contributions of various indices to the landscape disturbance index, $E_{i}$ (Table 2) [21]. The final parameters calculated for $E_{i}$ were $a=0.197, b=0.301, c=0.265, d=0.097$ and $e=0.140$.

\subsubsection{Landscape Fragility Index $\left(F_{i}\right)$}

Different landscape types represent different ecosystems and have different abilities to maintain the stability of ecological processes. Landscape types with higher ecological fragility are more sensitive to the outside world and have lower anti-interference ability and resilience. In contrast, landscape types with lower ecological fragility have good ecological stability, stronger anti-interference ability, and resilience $[47,48] . F_{i}$ indicates the landscape fragility index of land-use type $i$ [20]. Higher values of $F_{i}$ indicate lower landscape stability or higher ecosystem fragility. Previous research results have generally demonstrated that the $F_{i}$ of unused land and water areas is very high [23]. This indicates that these two landscape types quickly lose their original landscape structure and ecological functions under external disturbances. The $F_{i}$ of cultivated land and grassland is relatively low [21], while forest and construction land are the most stable landscape types. However, compared with other research objects, under the dual influences of rapid urbanization and ecological protection, the landscape fragility of construction land becomes relatively high [24]. Accordingly, the $F_{i}$ values of different landscape types were calculated by using the AHP method in MATLAB [49]. The final $F_{i}$ values of unused land, water area, cultivated land, grassland, construction land, and forest were $0.28,0.22,0.14,0.14,0.12$, and 0.10 , respectively. The consistency index $(C R)$ was 0.022 , meeting the requirement of $C R<0.10$ and indicating that the weight distribution was suitable.

\subsection{Spatial Statistical Analysis \\ 3.3.1. Semivariance Analysis}

As a spatial variable of landscape ecological risk, spatial heterogeneity has structural and random characteristics. The semivariance function is a very useful geostatistical method to measure the continuity of adjacent spatial variables [50]. The landscape ecological risk value was attributed to the corresponding landscape units. As a regional variable, 
the semivariance function compiled landscape ecological risk maps from 2000, 2010, and 2020 through the spatial evolution shown in Equation (3):

$$
\gamma(h)=\frac{1}{2 N(h)} \sum_{i=1}^{N(h)}\left[Z\left(x_{i}+h\right)-Z\left(x_{i}\right)\right]^{2}
$$

where $\gamma(h)$ is the experimental semivariance value at distance interval $h$, which describes the degree of autocorrelation that is present; $N(h)$ is the number of landscape units at lag distance $h$; and $Z\left(x_{i}\right)$ and $Z\left(x_{i}+h\right)$ are the sample values at locations $x_{i}$ and $x_{i}+h$ $(i=1,2, \ldots, N(h))$, respectively.

\subsubsection{Spatial Autocorrelation Analysis}

Spatial autocorrelation analysis is used to determine whether a variable correlates with the spatial distribution and the degree of correlation. The global Moran's I and local Moran's I of spatial autocorrelation were used to measure the spatial dependence of variables within this study [51]. The global Moran's I was used to test the spatial autocorrelation of attribute values of an element in the whole study area, with values falling within $[-1,1]$. As the absolute value of the global Moran's I approaches 1, the spatial autocorrelation is strongest [43]. The formula is shown in Equation (4):

$$
\text { Moran } / \mathrm{s} \mathrm{I}=\frac{n \sum_{i=1}^{n} \sum_{j=1}^{n} \omega_{\mathrm{ij}}\left(x_{i}-\bar{x}\right)\left(x_{j}-\bar{x}\right)}{\sum_{i=1}^{n}\left(x_{i}-\bar{x}\right) \sum_{i=1}^{n} \sum_{j=1}^{n} \omega_{\mathrm{ij}}}
$$

where $x_{i}$ and $x_{j}$ are the values of variable $x$ at adjacent space points, $\bar{x}$ is the average of the variables, $w_{i j}$ is the adjacent weight, and $n$ is the total number of risk points.

When Moran's I > 0, the spatial autocorrelation is positive and the attribute values of research units tend to aggregate. When Moran's I $=0$, there is no spatial autocorrelation determined and the observed values of spatial units are random. When Moran's $\mathrm{I}<0$, the spatial autocorrelation is negative the attribute values of research units are dispersed as discrete distributions.

The LISA index reflects the degree of correlation between a geographical phenomenon (or an attribute value of a local unit in the whole region) and the same phenomenon or attribute value in the adjacent local unit. Generally, the Moran's I term is decomposed and represented on different regional units to form a LISA clustering map. Analysis of LISA clustering maps yields high-high aggregation "hotspots" and low-low aggregation "cold spots" in the identified local spaces, and any abnormal local spatial characteristics can be assessed. The LISA index is calculated according to Equation (5):

$$
\operatorname{LISA}=Z_{i} \sum_{j=1}^{n} \omega_{i j} Z_{j},(i \neq j)
$$

where $Z_{i}$ and $Z_{i}$ are the standardized risk values of units $i$ and $j$, respectively, and $w_{i j}$ is the spatial weight matrix.

In the present study, spatial distribution patterns of ecological risk index in Xuzhou over three stages were estimated by using GeoDA [52]. A Moran's I scatter diagram was generated, and Moran's I and $Z$ values were extracted from the normalized statistical data $(p=0.001)$.

\section{Results}

\subsection{Land-Use Conversion Analysis}

Land development, accompanied by urban expansion, is a leading cause of ecological risk variation. Therefore, land-use composition during different stages was analyzed, with the land-use conditions in Xuzhou in 2000, 2010, and 2020 shown in Figure 2. The relative 
proportions of the various land-use types are shown in Figure 4. Land-use conversion matrixes were generated by using the Markov model (Tables 3 and 4).

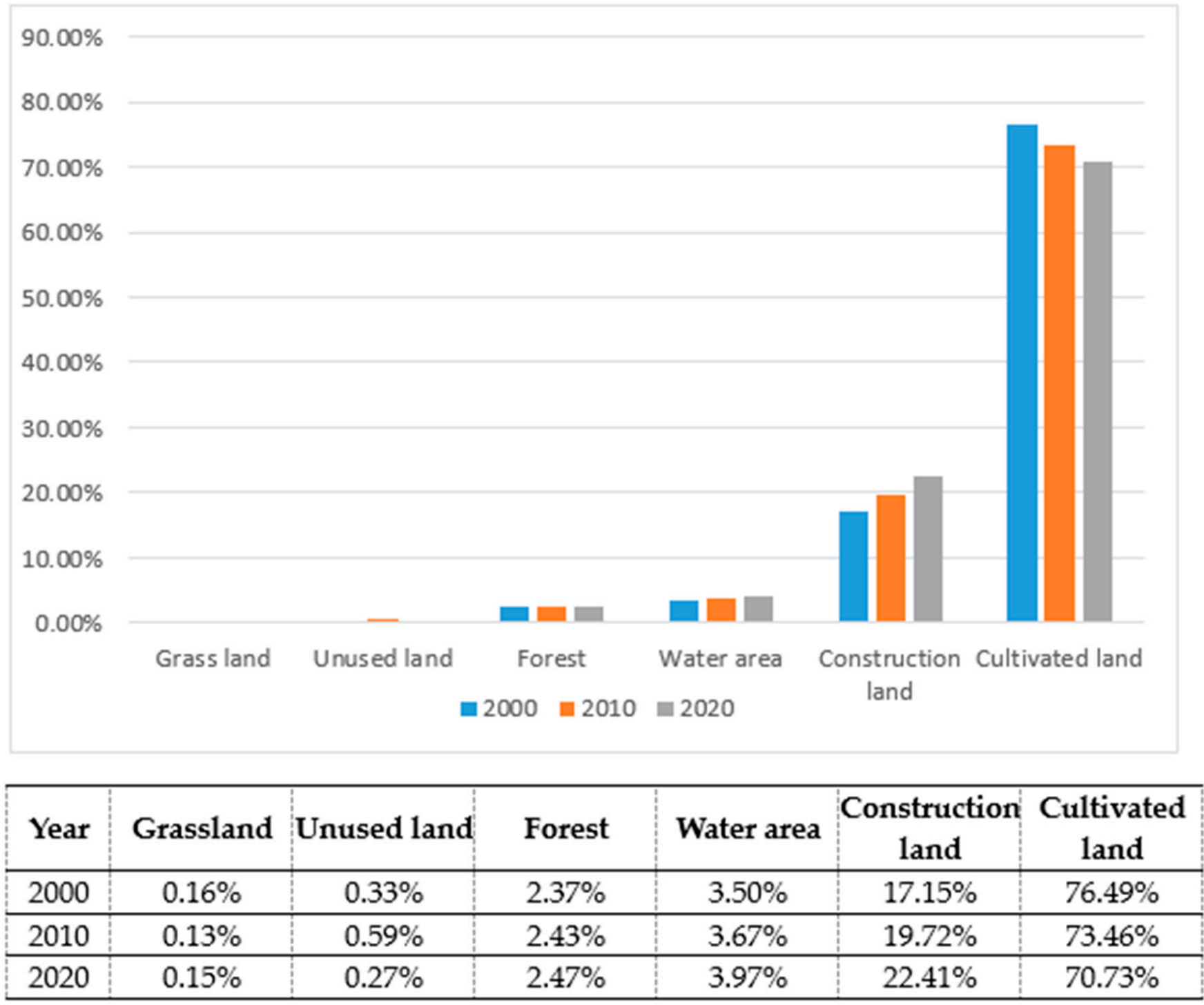

Figure 4. Land-use proportions of Xuzhou in 2000, 2010, and 2020.

Table 3. Land-use transition matrix of Xuzhou from 2000 to 2010.

\begin{tabular}{|c|c|c|c|c|c|c|}
\hline $2000 / 2010$ & $\begin{array}{c}\text { Unused } \\
\text { Land }\left(\mathbf{k m}^{2}\right)\end{array}$ & $\begin{array}{c}\text { Water Area } \\
\left(\mathbf{k m}^{2}\right)\end{array}$ & $\begin{array}{l}\text { Cultivated } \\
\text { Land }\left(\mathbf{k m}^{2}\right)\end{array}$ & $\begin{array}{c}\text { Grassland } \\
\left(\mathbf{k m}^{2}\right)\end{array}$ & $\begin{array}{l}\text { Construction } \\
\text { Land }\left(\mathbf{k m}^{2}\right)\end{array}$ & $\begin{array}{c}\begin{array}{c}\text { Forest } \\
\left(\mathbf{k m}^{2}\right)\end{array} \\
\end{array}$ \\
\hline Unused land & 20.04 & 0.01 & 0.90 & 0.61 & 15.95 & 0.00 \\
\hline Water area & 0.12 & 370.16 & 15.81 & 0.09 & 5.39 & 0.85 \\
\hline Cultivated land & 35.71 & 38.70 & 8147.55 & 7.62 & 326.94 & 11.47 \\
\hline Grassland & 1.91 & 0.17 & 0.78 & 2.19 & 12.38 & 0.08 \\
\hline Construction land & 8.27 & 2.32 & 60.30 & 2.90 & 1846.62 & 0.74 \\
\hline Forest & 0.29 & 0.12 & 3.52 & 0.86 & 1.32 & 258.99 \\
\hline
\end{tabular}

Note: Rows represent the transfer area of land-use type $i$ in 2000 to other land-use types in 2010; columns represent the transfer area of land-use type $i$ in 2010 from other land-use types in 2000. 
Table 4. Land-use transition matrix of Xuzhou from 2010 to 2020.

\begin{tabular}{|c|c|c|c|c|c|c|}
\hline $2010 / 2020$ & $\begin{array}{c}\text { Unused Land } \\
\left(\mathrm{km}^{2}\right)\end{array}$ & $\begin{array}{c}\text { Water Area } \\
\left(\mathrm{km}^{2}\right)\end{array}$ & $\begin{array}{l}\text { Cultivated } \\
\text { Land }\left(\mathrm{km}^{2}\right)\end{array}$ & $\begin{array}{c}\text { Grassland } \\
\left(\mathrm{km}^{2}\right)\end{array}$ & $\begin{array}{c}\text { Construction } \\
\text { Land }\left(\mathrm{km}^{2}\right)\end{array}$ & $\begin{array}{l}\text { Forest } \\
\left(\mathrm{km}^{2}\right)\end{array}$ \\
\hline Unused land & 21.6 & 0.29 & 1.58 & 0.54 & 42.27 & 0.06 \\
\hline Water area & 0.16 & 388.42 & 17.86 & 0.05 & 4.81 & 0.18 \\
\hline Cultivated land & 2.20 & 51.47 & 7806.95 & 2.22 & 359.94 & 6.07 \\
\hline Grassland & 0.15 & 0.01 & 0.66 & 3.60 & 8.96 & 0.88 \\
\hline $\begin{array}{c}\text { Construction } \\
\text { land }\end{array}$ & 5.67 & 3.26 & 92.54 & 10.25 & 2094.13 & 2.74 \\
\hline Forest & 0.00 & 0.96 & 3.50 & 0.00 & 0.75 & 266.91 \\
\hline
\end{tabular}

Note: Rows represent the transfer area of land-use type $i$ in 2000 to other land-use types in 2010; columns represent the transfer area of land-use type $i$ in 2010 from other land-use types in 2000 .

Between 2000 and 2010, the area of land-use types increased to varying degrees, except for cultivated land and grassland; these decreased by 338.68 and $3.24 \mathrm{~km}^{2}$, respectively. The area of construction land, unused land, water area, and forest increased by 287.47, 28.83, 19.16 , and $7.06 \mathrm{~km}^{2}$, respectively. Table 3 shows that, during this decade, the significant increase in construction land in the main urban areas of Xuzhou counties was mainly due to the transfer of $326.94 \mathrm{~km}^{2}$ of cultivated land. Additionally, a large amount of unused land appeared in the urban areas, which was mainly due to the transfer of $35.71 \mathrm{~km}^{2}$ of cultivated land. The mutual transformation of water area and cultivated land was pronounced, with the increase in water area being mainly due to the transfer of $38.70 \mathrm{~km}^{2}$ of cultivated land. From the perspective of landscape fragility, the area that was converted from high landscape fragility to lower values was $398.84 \mathrm{~km}^{2}$. The area that was converted from low landscape fragility to higher values was $157.29 \mathrm{~km}^{2}$.

From 2010 to 2020, other land-use types expanded to different extents, except for cultivated and unused land. The area of cultivated land and unused land decreased by 306.20 and $36.55 \mathrm{~km}^{2}$, respectively. The area of construction land, water area, forest, and grassland increased by $302.25,33.05,4.69$, and $2.39 \mathrm{~km}^{2}$, respectively. Table 4 shows that, that during this decade, construction land in the main urban areas of Xuzhou and its counties continued to increase, mainly due to the transfer of $359.94 \mathrm{~km}^{2}$ of cultivated land. A large amount of unused land in Yunlong and Gulou was transferred into construction land, and the largest outward transformation of unused land was to construction land, at $42.27 \mathrm{~km}^{2}$. The increase in water area was mainly due to the transfer of $51.47 \mathrm{~km}^{2}$ of cultivated land. From the perspective of landscape fragility, the area that was converted from high landscape fragility to lower values was $448.45 \mathrm{~km}^{2}$. The area that was converted from lower landscape fragility to higher values was $171.58 \mathrm{~km}^{2}$.

In Xuzhou, only cultivated land has continuously decreased. This has been the major source for the expansion of construction land, water area, and forest. From 2000 to 2020, $686.88 \mathrm{~km}^{2}$ of cultivated land was developed as construction land, resulting in the rapid growth of construction land. The area of construction land in 2020 was 1.31 times that in 2000, indicating that rapid urbanization was the major driving force of land use in Xuzhou. Activities such as ecological protection and ecological restoration have resulted in the frequent interconversion of cultivated land and water areas. From 2000 to 2020, 90.17 $\mathrm{km}^{2}$ of cultivated land was transferred into water area and $33.67 \mathrm{~km}^{2}$ of water area was transferred into cultivated land, most of which resulted from the ecological restoration of coal mining subsidence areas and landscape transformation along the lake. The area of unused land initially increased and then decreased, which aligned with rapid urbanization in Xuzhou. 


\subsection{Spatial Distribution and Changes of Landscape Ecological Risk}

\subsubsection{Landscape Index Dynamic Change Analysis}

The landscape indices of different landscape types are essential components of landscape ecological risk assessment. They are used to measure spatial patterns of change in land-use types at various stages. Landscape indices calculated at the district level in Xuzhou between 2000 and 2020 are listed in Table 5.

Table 5. Landscape metrics at class level in Xuzhou from 2000 to 2020.

\begin{tabular}{|c|c|c|c|c|c|c|}
\hline Type & Year & $C_{i}$ & $S_{i}$ & $D o_{i}$ & PAFRAC $_{i}$ & $N_{i}$ \\
\hline \multirow{3}{*}{ Unused land } & 2000 & 0.2034 & 3.8968 & 0.0307 & 1.1934 & 0.1335 \\
\hline & 2010 & 0.1406 & 2.4367 & 0.0369 & 1.1669 & 0.0964 \\
\hline & 2020 & 0.2521 & 4.8683 & 0.0306 & 1.1722 & 0.1518 \\
\hline \multirow{3}{*}{ Water area } & 2000 & 0.0755 & 0.7342 & 0.1260 & 1.4291 & 0.1145 \\
\hline & 2010 & 0.0745 & 0.7122 & 0.1301 & 1.4296 & 0.1111 \\
\hline & 2020 & 0.0683 & 0.6560 & 0.1337 & 1.4179 & 0.1063 \\
\hline \multirow{3}{*}{ Cultivated land } & 2000 & 0.0004 & 0.0120 & 0.4740 & 1.3319 & 0.0688 \\
\hline & 2010 & 0.0005 & 0.0125 & 0.4575 & 1.3051 & 0.0615 \\
\hline & 2020 & 0.0007 & 0.0155 & 0.4475 & 1.3083 & 0.0576 \\
\hline \multirow{3}{*}{ Grassland } & 2000 & 0.1285 & 4.5337 & 0.0106 & 1.1862 & 0.1044 \\
\hline & 2010 & 0.1647 & 5.6856 & 0.0114 & 1.1662 & 0.1243 \\
\hline & 2020 & 0.1428 & 4.8994 & 0.0110 & 1.2200 & 0.1214 \\
\hline \multirow{3}{*}{ Construction land } & 2000 & 0.0393 & 0.2395 & 0.3157 & 1.2410 & 0.0736 \\
\hline & 2010 & 0.0319 & 0.2012 & 0.3196 & 1.2541 & 0.0660 \\
\hline & 2020 & 0.0274 & 0.1747 & 0.3329 & 1.2671 & 0.0604 \\
\hline \multirow{3}{*}{ Forest } & 2000 & 0.0274 & 0.5379 & 0.0430 & 1.1760 & 0.0464 \\
\hline & 2010 & 0.0276 & 0.5332 & 0.0445 & 1.1696 & 0.0456 \\
\hline & 2020 & 0.0263 & 0.5161 & 0.0443 & 1.1636 & 0.0445 \\
\hline
\end{tabular}

During 2000-2020, the C, S, PAFRAC, and N indices of unused land first decreased and then increased, while the degree of $D o$ first increased and then decreased. There was a large area of unused land before and after 2010, the peak stage of urban expansion. The $C, S$, and $N$ indices of the water area decreased continuously, while the degree of Do continuously increased, and PAFRAC presented as an inverted V-shape. The number of scattered small water areas in Xuzhou decreased due to the water area in the coal mining subsidence area being controlled, and water areas becoming more contiguous. The $C$ and $S$ values of cultivated land continued to increase, whereas the degree of $D o$ and $N$ continued to decrease, and the minimum PAFRAC value was observed in 2010. The area of cultivated land declined to a large extent over the 20 years. Rapid urban expansion began in 2010, which significantly influenced the stability of cultivated land. For grassland, maximum values of $C, S$, the degree of $D o$, and $N$, as well as the minimum PAFRAC value, were all recorded in 2010; this reflected disturbance to grasslands peaking in 2010. For construction land, $C, S$, and $N$ values continued to decrease, while the degree of Do and PAFRAC continued to increase. Construction land use has been concentrating and expanding, with the edges of plaques expanding due to enlarging central urban areas in cities and counties. Many plaques were absorbed into larger ones. For forest areas, $C$ and the degree of $D o$ first increased and then decreased. In contrast, $S, P A F R A C$, and $N$ continued to decline. The forest areas were aggregated to afford protection from dispersed expansion, and stability gradually increased. 
The landscape disturbance indices of different land-use types over the two decades were calculated, using the landscape indices. An ecological risk index model was then established, and the risk value of the landscape units was determined. The ecological risk value of landscape units in 2000 ranged from $2.68 \times 10^{-2}$ to $15.96 \times 10^{-2}$, with an average value of $3.28 \times 10^{-2}$. The ecological risk value of landscape units in 2010 ranged from $2.67 \times 10^{-2}$ to $21.71 \times 10^{-2}$, with an average value of $3.23 \times 10^{-2}$. The ecological risk value of landscape units in 2020 ranged from $2.62 \times 10^{-2}$ to $11.70 \times 10^{-2}$, with an average value of $3.18 \times 10^{-2}$. Therefore, the minimum and average ecological risk values of landscape units decreased decade by decade, clearly revealing a decline in ecological risk and a gradual improvement to the ecological environment for Xuzhou over the two decades.

\subsubsection{Distribution and Changes of Landscape Ecological Risk}

Semivariance functions were used to enable the spatial interpolation of the ecological risk indices. Spatial fitting is a crucial step in using semivariance functions, with the optimal fitting of semivariance functions determined using the GS + 9.0 [53]. Combining the model fitting effects with consideration of $\mathrm{R}^{2}$ and RSS, ecological risk spatial analyses for 2000, 2010, and 2020 were produced that were derived from the exponential model [28]. Spatial interpolation maps of landscape ecological risks over the two decades were generated using the Kriging interpolation method in Arc GIS 10.2. The natural breakpoint method was used to divide the ecological risk values of each group and then the breakpoints of each group were compared to determine the final breakpoint values of $0.0295,0.0345,0.0485$, and 0.0695 . These breakpoints categorized landscape ecological risk values into five levels: extremely high, high, medium, low, and extremely low (Figure 5).

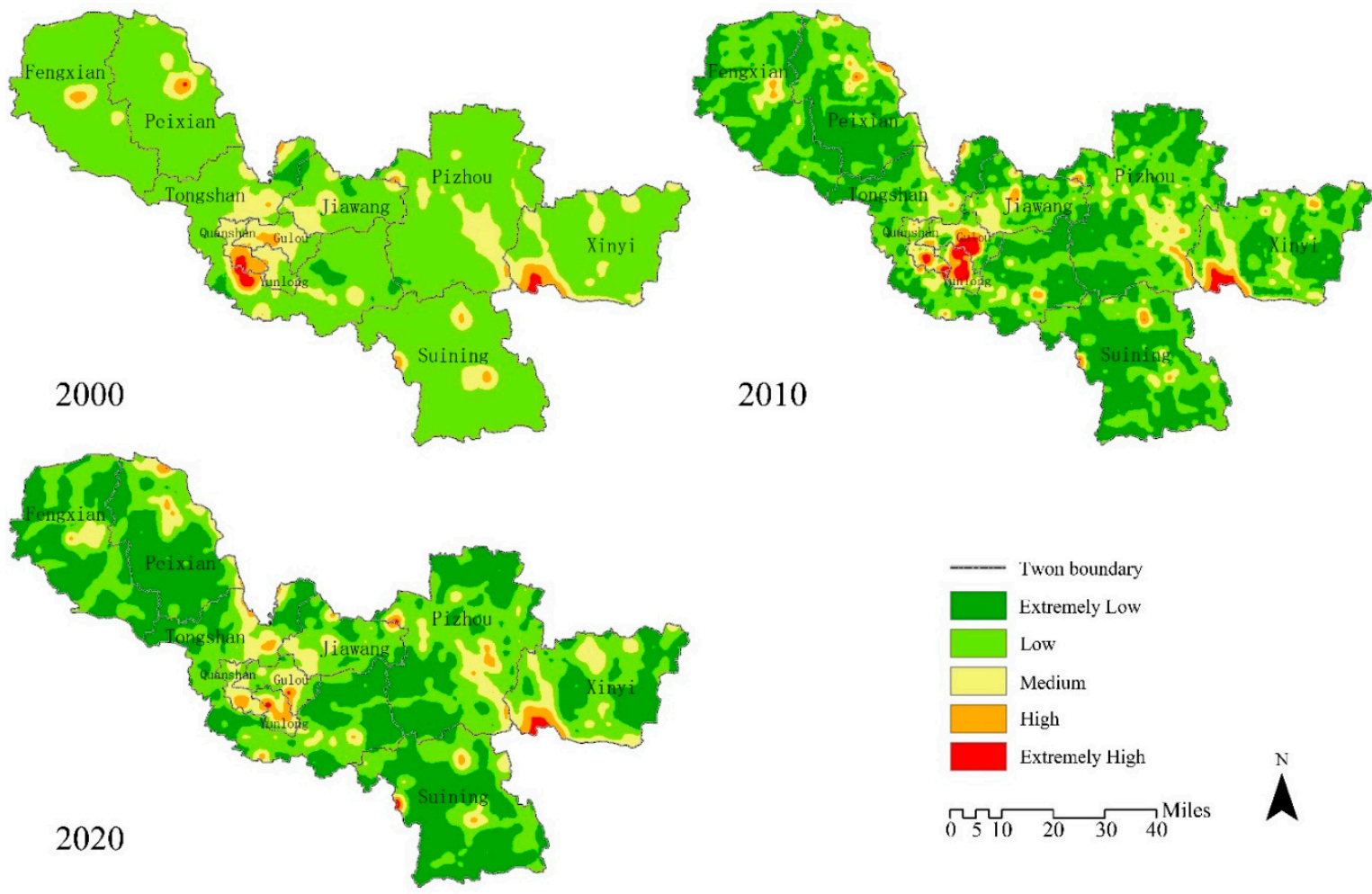

Figure 5. Spatial interpolation maps for the ERI in Xuzhou from 2000 to 2020.

In 2000, the extremely low-risk regions were mainly distributed in the hilly forest areas of Xuzhou. The medium-risk regions were primarily in urban areas and central urban areas of counties, coal mining subsidence areas, and river and reservoir areas that were significantly influenced by human activities. The high-risk and extremely high-risk regions were mainly at urban edges with high urban construction intensity and also the water 
area of Luoma Lake. In 2010, the extremely low-risk regions covered predominantly rural areas of the original hilly forest, and many extremely low-risk regional plaques formed. The medium-risk regions were still distributed within the urban area, urban areas of counties, coal mining subsidence areas, rivers, and reservoir areas but were decreased. The previously high-risk and extremely high-risk regions along the urban expansion directions were transferred into other land-use types. In 2020, the extremely low-risk regions had expanded and consolidated, and many extremely low-risk regional plaques in villages and towns became contiguous. The medium-risk regions were considerably larger but still distributed in their original locations. In urban areas, the high-risk and extremely high-risk regions decreased in area, and their geographical centers had shifted. The risk values of water areas were reduced, but Luoma Lake was still an extremely high-risk region.

The high-risk regions in 2000 and 2010 (Figure 6) mainly included water areas, unused land, and construction land. In 2020, the extremely high-risk regions were primarily the water areas, cultivated land, and unused land regions. In 2000, 2010, and 2020, the water area occupied $44.85 \%, 37.40 \%$, and $66.64 \%$ of the total area, respectively. In extremely high-risk regions, the proportion of construction land was lower than that of unused and cultivated lands at each time point. Unused land accounted for the greatest proportion in 2010, reaching 25.54\%, and the extremely low-risk regions mainly contained cultivated land, forest, and construction land. Cultivated land occupied the highest proportion at $48.42 \%, 70.29 \%$, and $68.54 \%$ in 2000,2010 , and 2020, respectively. In extremely low-risk regions, the ratio of construction land increased over the twenty years from $5.23 \%$ to $16.81 \%$ and then to $18.47 \%$.

\subsection{Landscape Ecological Risk Conversion Analysis}

Statistical analyses of each ecological risk are shown in Table 6. Over the 20 years between 2000 and 2020, the area of extremely low-risk regions increased with a maximal growth of $4616.00 \mathrm{~km}^{2}$ in 2010 . The area of low-risk regions decreased over the twenty years, with a maximal reduction of $42,848.88 \mathrm{~km}^{2}$ in 2010 . The area of medium-risk regions was a minimum $\left(1186.75 \mathrm{~km}^{2}\right)$ in 2010 , and the area of high-risk regions initially increased and then consistently decreased from $243.54 \mathrm{~km}^{2}$ in 2010 to $216.85 \mathrm{~km}^{2}$ in 2020 . The area of extremely high-risk regions reached a maximum $\left(117.75 \mathrm{~km}^{2}\right)$ in 2010 and then decreased to $32.90 \mathrm{~km}^{2}$ in 2020. Except for the increase in the are extremely high-risk regions due to urban expansion in 2010, there was a downward trend in the overall risk levels in Xuzhou, indicative of the gradually improving ecological environment.

Table 6. The changes of landscape ecological risk in Xuzhou from 2000 to 2020.

\begin{tabular}{|c|c|c|c|c|c|}
\hline Year & $\begin{array}{l}\text { Extremely Low } \\
\left(\mathrm{km}^{2}\right)\end{array}$ & $\begin{array}{c}\text { Low } \\
\left(\mathrm{km}^{2}\right)\end{array}$ & $\underset{\left(\mathrm{km}^{2}\right)}{\text { Medium }}$ & $\begin{array}{l}\text { High } \\
\left(\mathbf{k m}^{2}\right)\end{array}$ & $\begin{array}{c}\text { Extremely High } \\
\left(\mathrm{km}^{2}\right)\end{array}$ \\
\hline 2000 & 180.60 & 9142.48 & 1585.71 & 237.93 & 55.55 \\
\hline 2010 & 4796.60 & 4857.60 & 1186.75 & 243.54 & 117.74 \\
\hline 2020 & 5046.86 & 4541.15 & 1364.50 & 216.85 & 32.90 \\
\hline
\end{tabular}

The conversions between different ecological risk grades between 2000 and 2010 are shown in Table 7. The area that was converted from a low-risk to an extremely low-risk grade was the most significant at $4523.80 \mathrm{~km}^{2}$, with an annual average conversion of $458.38 \mathrm{~km}^{2}$. The ecological risk of most Xuzhou regions improved during the 20-year transformation period that was investigated. The conversion of medium-risk regions accounted for the greatest increase in low-risk regions, with an area of $511.78 \mathrm{~km}^{2}$. Conversely, the conversion of low-risk regions accounted for the greatest proportion of the increase in medium-risk regions, with an area of $238.08 \mathrm{~km}^{2}$. The conversion of medium-risk regions accounted for the greatest proportion of the increase in high-risk regions, with an area of $126.29 \mathrm{~km}^{2}$. The total risk area accounted for the highest proportion in the extremely high-risk regions, with an area of $54.92 \mathrm{~km}^{2}$. The total area that was converted from a 
low-risk to a high-risk grade was $492.33 \mathrm{~km}^{2}$, which occurred primarily in urban areas and urban areas of counties. This change is mainly caused by urban construction. The total conversion area from a high-risk to a low-risk grade was $5294.86 \mathrm{~km}^{2}$, which was mainly concentrated in rural areas that were only slightly affected by urban construction. The risk values of rural areas decreased because of changes in landscape patterns.

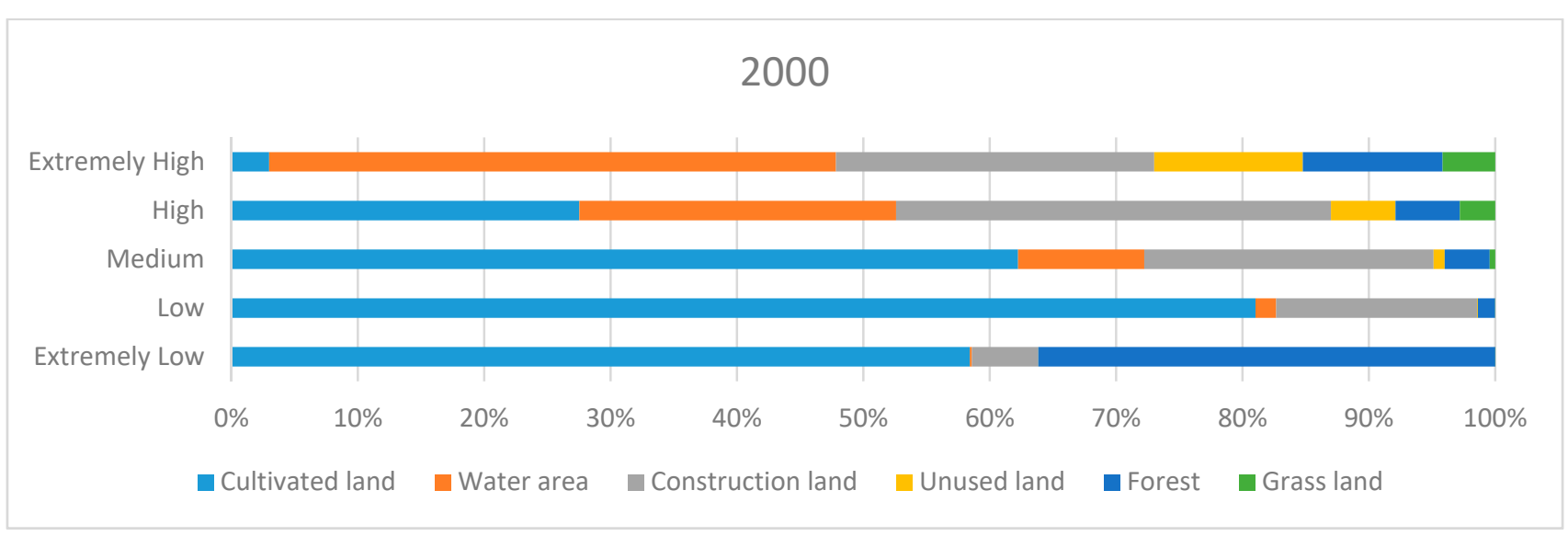

(a)

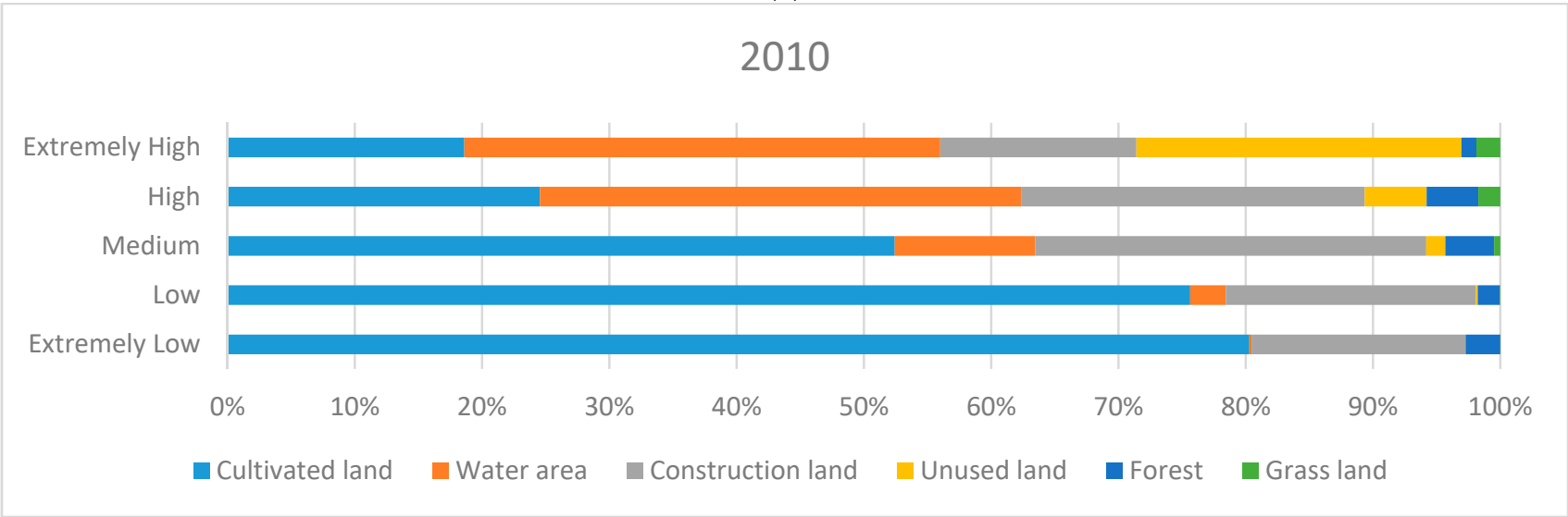

(b)

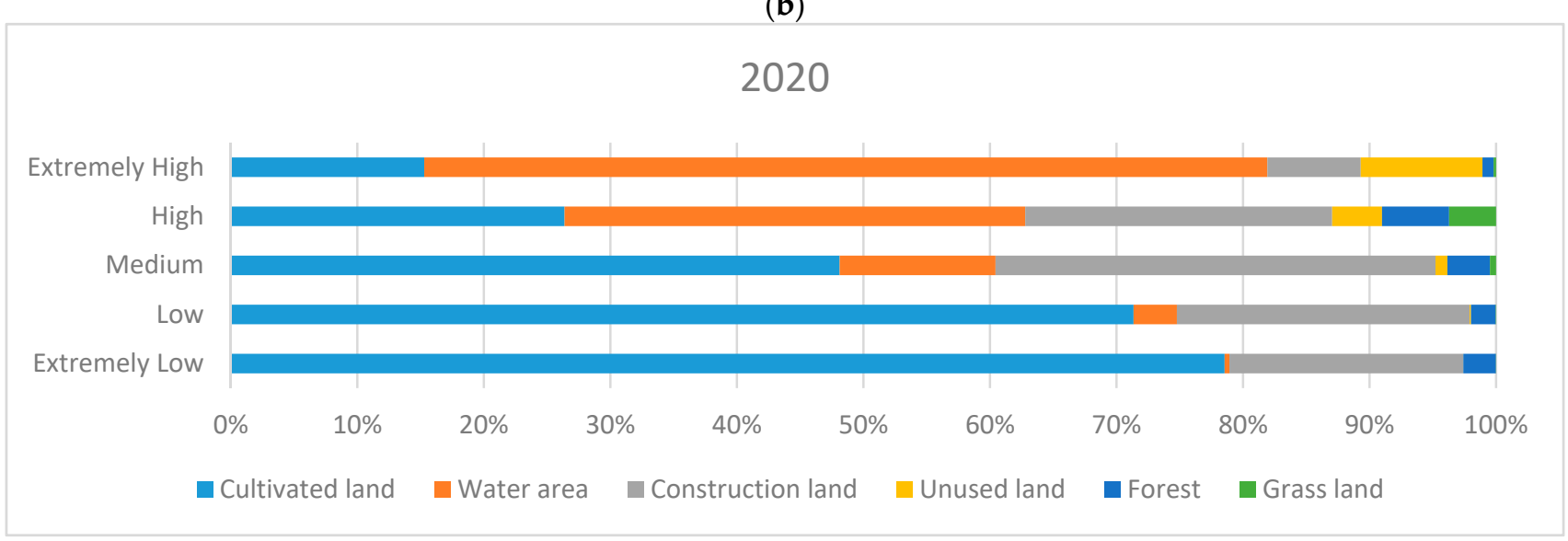

(c)

Figure 6. Land-use composition in various risk regions in 2000 (a), 2010 (b), and 2020 (c). 
Table 7. Ecological risk transition matrix of Xuzhou from 2000 to 2010.

\begin{tabular}{|c|c|c|c|c|c|}
\hline $2000 / 2010$ & $\begin{array}{l}\text { Extremely Low } \\
\left(\mathrm{km}^{2}\right)\end{array}$ & $\begin{array}{c}\text { Low } \\
\left(\mathrm{km}^{2}\right)\end{array}$ & $\begin{array}{l}\text { Medium } \\
\left(\mathrm{km}^{2}\right)\end{array}$ & $\begin{array}{l}\text { High } \\
\left(\mathrm{km}^{2}\right)\end{array}$ & $\begin{array}{l}\text { Extremely High } \\
\qquad\left(\mathrm{km}^{2}\right)\end{array}$ \\
\hline Extremely Low & 162.26 & 16.55 & 1.76 & 0 & 0 \\
\hline Low & 4583.80 & 4289.97 & 238.08 & 15.86 & 14.34 \\
\hline Medium & 46.53 & 511.78 & 846.11 & 126.29 & 54.92 \\
\hline High & 3.69 & 30.42 & 87.03 & 92.25 & 24.53 \\
\hline Extremely High & 0.09 & 8.70 & 13.71 & 9.11 & 23.93 \\
\hline
\end{tabular}

Note: Rows represent the transfer area of level $i$ in 2000 to each other level in 2010; columns represent the transfer area of level $i$ in 2010 from each other level in 2000.

The conversion between different ecological risk grades from 2010 to 2020 is shown in Table 8 . The area that was converted from a low-risk to an extremely low-risk grade was $869.23 \mathrm{~km}^{2}$. The conversion of extremely low-risk regions accounted for most of the increase in low-risk regions, with an area of $624.20 \mathrm{~km}^{2}$. The conversion of low-risk regions accounted for the greatest proportion of the increase in medium-risk regions, with an area of $346.45 \mathrm{~km}^{2}$. The conversion of medium-risk regions accounted for the greatest proportion of the increase in high-risk regions, with an area of $67.60 \mathrm{~km}^{2}$. Similarly, the conversion of high-risk regions accounted for the greatest proportion of the increase in extremely high-risk regions, with an area of $8.69 \mathrm{~km}^{2}$. Except for the extremely low-risk regions, the increased area of different risk grades was mainly due to conversion from the immediately lower grade, indicating a stable overall risk variation pattern. The total area that was converted from a low-risk to a high-risk grade was $1084.84 \mathrm{~km}^{2}$, and the total area that was converted from a high-risk to a low-risk grade was $1393.53 \mathrm{~km}^{2}$. Both conversion trends occurred predominantly in urban areas and central urban areas of counties where urban construction significantly impacted conversions.

Table 8. Ecological risk transition matrix of Xuzhou from 2010 to 2020.

\begin{tabular}{|c|c|c|c|c|c|}
\hline $2010 / 2020$ & $\begin{array}{c}\text { Extremely Low } \\
\left(\mathbf{k m}^{2}\right)\end{array}$ & $\begin{array}{c}\text { Low } \\
\left(\mathrm{km}^{2}\right)\end{array}$ & $\begin{array}{c}\text { Medium } \\
\left(\mathrm{km}^{2}\right)\end{array}$ & $\begin{array}{l}\text { High } \\
\left(\mathrm{km}^{2}\right)\end{array}$ & $\begin{array}{c}\text { Extremely High } \\
\left(\mathrm{km}^{2}\right)\end{array}$ \\
\hline Extremely Low & 4150.73 & 624.20 & 20.49 & 1.02 & 0 \\
\hline Low & 869.23 & 3626.00 & 346.45 & 15.68 & 0.09 \\
\hline Medium & 25.10 & 259.22 & 834.13 & 67.60 & 0.62 \\
\hline High & 1.40 & 16.45 & 127.91 & 89.05 & 8.69 \\
\hline Extremely High & 0.21 & 15.14 & 35.40 & 43.47 & 23.49 \\
\hline
\end{tabular}

Note: Rows represent the transfer area of level $i$ in 2010 to each other level in 2020; columns represent the transfer area of level $i$ in 2020 from each other level in 2010.

\subsection{Spatial Autocorrelation Landscape Ecological Risk Index}

The global autocorrelation of landscape ecological risk can meaningfully reflect spatial changes. According to the ecological risk values during the study period, Moran's I at different distances were calculated, as shown in Figure 7. The Moran's I values were all greater than 0 , indicating that the spatial autocorrelation of the ecological risk index (ERI) was always positive. Moran's I at a distance of $2 \mathrm{~km}$ was the largest and declined with increasing spatial distance, indicating that higher spatial distance resulted in lower spatial autocorrelation. When the spatial distance was beyond $20 \mathrm{~km}$, the spatial pattern of the ERI approached a random distribution. Moran's I showed a consistent variation trend in 2000, 2010, and 2020 when the spatial distance exceeded $5 \mathrm{~km}$. When considering Moran's I at equal distances, the values were smallest in 2020 and highest in 2010. 


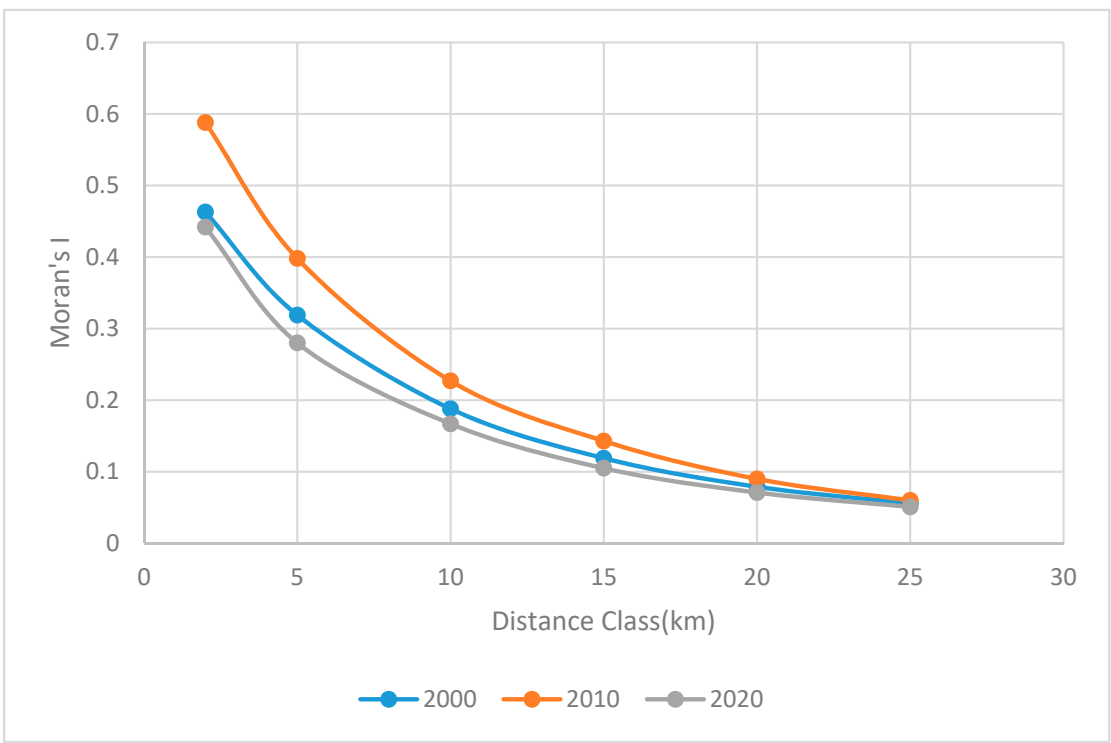

Figure 7. Moran's I value for the ERI under different granularities.

Local spatial autocorrelation for the ERI is shown in Figure 8. From 2000 to 2020, the spatial distribution scale of $\mathrm{L}-\mathrm{L}$ clusters was similar and mostly in rural and hilly forest regions. The distribution of $\mathrm{L}-\mathrm{L}$ clusters was the same in Xinyi, Pizhou, and Fengxian, and it differed slightly in Peixian Suining and Tongshan. $\mathrm{H}-\mathrm{H}$ clusters were mainly focused in urban areas and the Luoma Lake area, accompanied by significant variations. $\mathrm{H}-\mathrm{H}$ clusters in the urban area decreased gradually, and their center shifted toward the southeast as they became distributed along the southeast line of Xuzhou in 2020. In Peixian, $\mathrm{H}-\mathrm{H}$ clusters initially expanded along the coastline of Weishan Lake and then divided into two small clusters towards the northwest. The $\mathrm{H}-\mathrm{H}$ cluster in Tongshan near Weishan Lake gradually expanded, a new $\mathrm{H}-\mathrm{H}$ cluster formed in the main urban area of Xinyi in 2020, and the $\mathrm{H}-\mathrm{H}$ cluster in Luoma Lake changed slightly.

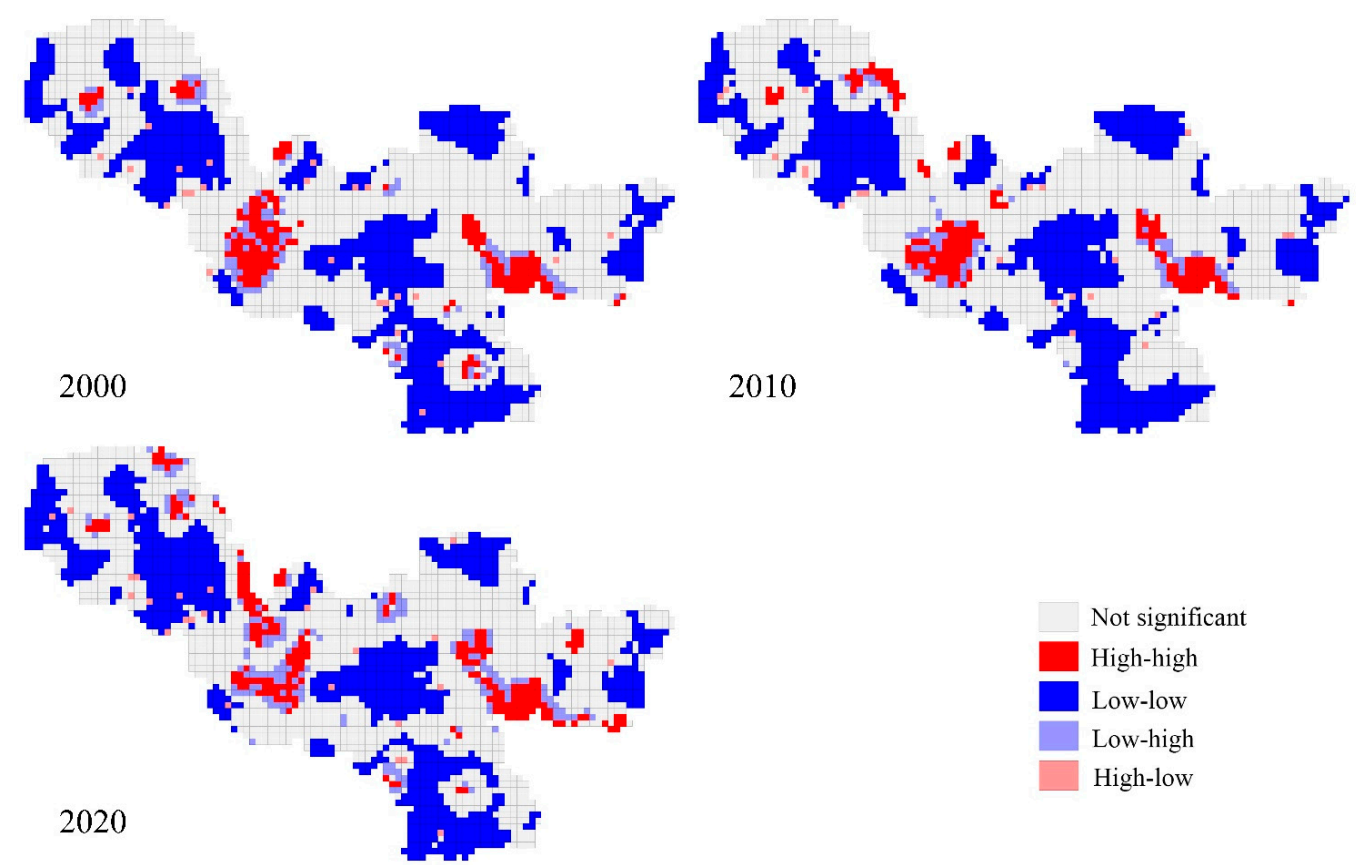

Figure 8. Spatial cluster maps using local spatial autocorrelation for ERI in Xuzhou from 2000 to 2020. 


\section{Discussion}

Resource exploitation induces urban development and causes extreme changes to land-use structures in cities. When resources are exhausted and the increasing urban development requirements impact the ecological environment, many traditional resourcebased cities gradually enter the transformation period. Once the new demands of urban development commence, changes in urban landscape patterns become more evident. Landscape ecological risk assessments provide an integrated perspective on the transformation period of resource-based cities. As a resource-based city, Xuzhou is transforming from a resource-based industrial city to an eco-friendly city. The land-use coefficients and landscape ecological risk values are representative of the evolving urban development during this transition.

Consistent with other studies during the same period [32,54], urbanization progress in China was an essential motivation for land-use changes between 2000 and 2020. Consequently, construction land became the land-use type with the highest growth rate. The land-use conversion matrix indicated that cultivated land was the major source of annual growth in construction land between 2000 and 2020. The land-use changes caused by urban expansion being conversions from either cultivated land to construction land or cultivated land to unused land and then to construction land. All the land-use conversions showed that urban development disrupted the landscape ecology of cities.

However, in contrast to other studies [32,33], the research cycle in this study was mainly based on three time periods: before the closure of the Xuzhou mine, immediately prior to rapid expansion, and at the beginning of ecological restoration. Among these periods, 2010 was selected as the research object because it was just before the rapid expansion of Xuzhou. A large amount of cultivated land was requisitioned for construction and was in a state of disuse. This caused a sharp increase in the area of Xuzhou's extremely high-risk areas by a factor of two in 2010, reflecting the significant impact of urban expansion. Moreover, in contrast to other studies [33,36], this study selected five landscape pattern indices to construct the landscape ecological risk index and used the entropy weight method and AHP to determine their weightings. The calculated results were consistent with the actual development of Xuzhou and, significantly, revealed the characteristics of ecological risks as follows.

Economic factors and government policies, especially urban planning, resulted in the development of the main urban area of Xuzhou in the southeast. Between 2000 and 2020, the $\mathrm{H}-\mathrm{H}$ clusters in Xuzhou's urban areas moved toward the southeast continuously and L-L clusters in Eastern Tongshan decreased in 2010. By 2020, the H-H cluster had moved eastward by $8 \mathrm{~km}$ and the $\mathrm{H}-\mathrm{H}$ clusters in older urban areas continued to decline. This indicates that the increased ecological risk at the border regions of urban expansion will probably continue to grow. Changes in H-H clusters in counties' main urban areas caused significant fluctuations in the ecological risk of rural regions surrounding the main urban area. In contrast, L-L cluster distribution in distant rural areas was relatively stable and only slightly influenced by urbanization changes. Therefore, Xuzhou should take measures to limit the rapid expansion of the city and optimize the urban layout.

Consistent with other studies during the same period [30,55], during the twenty years of the present study the ecological problems arising from coal mining still affected the landscape ecology of Xuzhou. The subsidence area caused by coal mining limited the flexibility of land-use change. Hence, important coal-mining areas were in the mediumrisk regions. In 2010, Xuzhou began the reclamation and ecological restoration of the Jiuli Lake coal-mining subsidence area, which turned the waters northwest of Quanshan into cultivated land and construction land. During the same period, the coal-mining subsidence area in the southwestern area of Jiawang expanded and scattered water areas increased, requiring timely intervention for ecological restoration. In 2020, the ecological restoration of the Jiuli Lake coal-mining subsidence area was completed. The coal-mining subsidence area in the northwest of Quanshan had reduced water areas and increased construction land. Similarly, ecological restoration of the coal-mining subsidence area 
in Southwestern Jiawang was completed. The relatively scattered waters of the Pan'an Lake area had disappeared, forming a larger water area. The changes in landscape pattern indices reflected this evolution through steady reductions of $C, S$, and $N$ in water areas; steady increases in Do; and an inverted V-shaped variation in PAFRAC. The variations in all of these indices reflected the gradually increasing contiguous water areas. Over these two decades, Xuzhou has completed ecological restoration projects in the coal-mining subsidence areas of Jiuli Lake and Pan'an Lake and transformed them into scenic ecotourism areas. While solving regional ecological problems, this has also brought new development driving forces to the surrounding area.

This study confirmed that the ecological problems arising from rapid urban expansion and coal mining were the main sources of ecological risks during the transformation of resource-based cities. Of these, the rapid urban expansion brings about short-term ecological risk, while the ecological problems caused by coal mining are of longer duration. However, scientific planning can effectively improve the landscape ecology of a city and reduce the overall landscape ecological risks from the perspective of the landscape pattern. From the perspective of sustainable development, ecological protection and restoration are necessary investments for resource-based cities during the transformation period. While solving ecological risks, this can create a new focus on sustainable development and have a longer-lasting impact.

This study explored the characteristics of land use and landscape ecological risks during the transformation of a resource-based city. The evaluation method used in this study can be used to evaluate the ecological risks of other resource-based cities during their transformation or of other cities during rapid expansion. The results clearly indicate the impact of land-use changes on the ecosystem, and the indicators and weights can be adjusted as appropriate to different research contexts. Some limitations, however, need to be acknowledged. For example, this study was based on the interpretation of remote-sensing land-use classification data. There are errors in such data and in personal interpretation, which may have resulted in uncertainty in the evaluation results. Therefore, during processing, errors in the remote-sensing data in different periods were eliminated as much as possible, and a unified standard was adopted for land-use classification to ensure the accuracy of the data. Furthermore, the spatiotemporal evolution of ecological risk is a comprehensive and complex process that is also affected by population, economy, and production. Therefore, further research and analysis are needed to develop a complete and comprehensive ecological-risk-assessment method.

\section{Conclusions}

This study analyzed the spatiotemporal variation of land use and landscape ecological risk of a resource-based city in China. The main conclusions are as follows:

1. Cultivated land surrounding the urban area of Xuzhou and primarily urban counties were predominantly occupied by construction land from 2000 to 2020. Urbanization was the major driver of land-use changes. Due to rapid urban expansion, all landscape ecological risk indices relating to expanding urban borders increased sharply. The extremely high-risk regions being significantly affected by urban construction.

2. The ecological effects of the coal mining subsidence area were relatively profound, with short-term changes to the land-use types in this area being difficult. Landscape reconstruction based on ecological restoration technologies could improve the landscape pattern indices and the local ecological environment.

3. LISA results demonstrated that landscape ecological risks of rural areas near urban areas of Xuzhou and rural border areas of significant urban expansion were mutually influential. However, the landscape ecological risk for rural regions that were far from an urban area or primary urban regions in counties was relatively stable.

4. Scientific planning improves the overall ecosystem of a city. In Xuzhou, changes in landscape patterns resulted in a downward trend in the overall landscape ecological risk. 
These research results provide a reference for land-use planning and landscape ecological risk control during the transition period of resource-based cities. Controlling landscape ecological risks brought about by urbanization will become the focus of future resourcebased city transformation. Xuzhou should aim for smart growth, avoid the rapid expansion of urban construction land, and prevent urban expansion from bringing drastic changes in land use. Through scientific and reasonable planning, optimization of the distribution of cities and towns will improve their ecosystems and reduce the landscape ecological risks brought about by urbanization. As for the ecological damage resulting from coal mining, ecological restoration should be carried out as soon as possible. This will avoid the aggravation of ecological damage, which will harm economic development and form a vicious cycle. The problem of landscape ecological risk should be dealt with from a sustainability perspective and be transformed into a new force for the long-term development of the city.

Author Contributions: All the authors contributed equally to this work. Conceptualization, D.W. and X.J.; data curation, D.W. and X.J.; formal analysis, D.W. and C.L.; methodology, C.L.; software, C.L.; writing-original draft, D.W.; writing-review and editing, Y.G. All authors have read and agreed to the published version of the manuscript.

Funding: This research was funded by the National key research and development Program of China (No. 2018YFD1100200).

Conflicts of Interest: The authors declare no conflict of interest.

\section{References}

1. WCED. Report of the world commission on environment and development: Our common future (the Brundtland Report). Med. Confl. Surviv. 1987, 17, 1-91.

2. Xu, Y.; Xu, X.; Tang, Q. Human activity intensity of land surface: Concept, methods and application in China. J. Geogr. Sci. 2016, 26, 1349-1361. [CrossRef]

3. Landis, W.G. Ecological risk assessment conceptual model formulation for nonindigenous species. Risk Anal. 2004, 24, 847-858. [CrossRef]

4. Zhou, R.J.; Zhang, Y.Z.; He, H.C. Ecological risk assessment based on land use changes in the coastal area in Yancheng city. Geogr. Res. 2016, 35, 1017-1028.

5. Qiu, B.K.; Li, H.L.; Zhou, M.; Zhang, L. Vulnerability of ecosystem services provisioning to urbanization: A case of China. Ecol. Indic. 2015, 57, 505-513. [CrossRef]

6. Kicińska, A.; Mamak, M. Health risks associated with municipal waste combustion on the example of Laskowa commune (Southern Poland). Hum. Ecol. Risk Assess. 2017, 23, 2087-2096. [CrossRef]

7. Faber, J.H.; Van Wensem, J. Elaborations on the use of the ecosystem services concept for application in ecological risk assessment for soils. Sci. Total Environ. 2012, 415, 3-8. [CrossRef] [PubMed]

8. Forbes, V.E.; Calow, P. Developing predictive systems models to address complexity and relevance for ecological risk assessment. Integer. Environ. Assess. Manag. 2013, 9, e75-e80. [CrossRef]

9. Peng, J.; Dang, W.X.; Liu, Y.X.; Zong, M.L.; Hu, X.X. Review on landscape ecological risk assessment. Acta Geogr. Sin. 2015, 70, 664-677.

10. Gong, J.; Yang, J.; Tang, W. Spatially explicit landscape-level ecological risks induced by land use and land cover change in a national ecologically representative region in China. Int. J. Environ. Res. Public Health 2015, 12, 14192-14215. [CrossRef] [PubMed]

11. Jawed, T.; Ahmad, N.; Mashiatullah, A. Heavy metals contamination and ecological risk assessment in surface sediments of Namal lake, Pakistan. Pol. J. Environ. Stud. 2018, 27, 675-688.

12. Hope, B.K. An examination of ecological risk assessment and management practices. Environ. Int. 2006, 32, 983-995. [CrossRef]

13. Landis, W.G.; Wiegers, J.K. Ten years of the relative risk model and regional scale ecological risk assessment. Hum. Ecol. Risk Assess. 2007, 13, 25-38. [CrossRef]

14. Suter, G.W. Endpoints for regional ecological risk assessments. Environ. Manag. 1990, 14, 9-23. [CrossRef]

15. Bayliss, P.; Van Dam, R.A.; Bartolo, R.E. Quantitative ecological risk assessment of the Magela Creek Floodplain in Kakadu National Park, Australia: Comparing point source risks from the ranger uranium mine to diffuse landscape-scale risks. Hum. Ecol. Risk Assess. 2012, 18, 115-151. [CrossRef]

16. Dezhkam, S.; Jabbarian, A.B.; Darvishsefat, A.A.; Sakieh, Y. Performance evaluation of land change simulation models using landscape metrics. Geocarto Int. 2017, 32, 623-677. [CrossRef]

17. Ayre, K.K.; Landis, W.G. A Bayesian approach to landscape ecological risk assessment applied to the Upper Grande Ronde Watershed, Oregon. Hum. Ecol. Risk Assess. Int. J. 2012, 18, 946-970. [CrossRef]

18. Guo, S.Z.; Bai, H.Y.; Meng, Q.; Huang, X.Y.; Qi, G.Z. Landscape pattern change and its response to anthropogenic disturbance in the Qinling Mountains during 1980 to 2015. Chin. J. Appl. Ecol. 2018, 29, 4080-4088. 
19. Lin, Y.; Hu, X.; Zheng, X.; Hou, X.; Zhang, Z.; Zhou, X.; Qiu, R.; Lin, J. Spatial variations in the relationships between road network and landscape ecological risks in the highest forest coverage region of China. Ecol. Indic. 2019, 96, 392-403. [CrossRef]

20. Fan, J.; Wang, Y.; Zhou, Z.; You, N.; Meng, J. Dynamic ecological risk assessment and management of land use in the middle reaches of the Heihe river based on landscape patterns and spatial statistics. Sustainability 2016, 8, 536. [CrossRef]

21. Li, Y.; Huang, S. Landscape ecological risk responses to land use change in the Luanhe river basin, China. Sustainability 2015, 7, 16631-16652. [CrossRef]

22. Zhou, Q.; Zhang, X.; Wang, Z. Land use ecological risk evaluation in Three Gorges Reservoir Area based on normal cloud model. Trans. Chin. Soc. Agric. Eng. 2014, 30, 289-297.

23. Li, J.; Pu, R.; Gong, H.; Luo, X.; Ye, M.; Feng, B. Evolution characteristics of landscape ecological risk patterns in coastal zones in Zhejiang Province, China. Sustainability 2017, 9, 584. [CrossRef]

24. Zhou, D.; Shi, P.; Wu, X.; Ma, J.; Yu, J. Effects of urbanization expansion on landscape pattern and region ecological risk in Chinese coastal city: A case study of Yantai city. Sci. World J. 2014. [CrossRef]

25. Kanwar, P.; Bowden, W.B.; Greenhalgh, S. A regional ecological risk assessment of the Kaipara Harbour, New Zealand, using a relative risk model. Hum. Ecol. Risk Assess. 2015, 21, 1123-1146. [CrossRef]

26. Shi, H.; Yang, Z.; Han, F.; Shi, T.; Li, D. Assessing landscape ecological risk for a world natural heritage site: A case study of Bayanbulak in China. Pol. J. Environ. Stud. 2015, 24, 269-283. [CrossRef]

27. Xiao, L.; Tian, G. Eco-risk Assessment of Land Use in Tianjin City. Chin. J. Ecol. 2014, 33, 469-476.

28. $\mathrm{Hu}, \mathrm{X} . ; \mathrm{Xu}, \mathrm{H}$. A new remote sensing index for assessing the spatial heterogeneity in urban ecological quality: A case from Fuzhou city, China. Ecol. Indic. 2018, 89, 11-21. [CrossRef]

29. Zhang, T.; Liu, Y.X.; Peng, J.; Wang, Y.L. Correlation of the landscape ecological risk on multi-scales in Shenzhen City. Chin. J. Ecol. 2016, 35, 2478-2486.

30. Dai, W.; Dong, J.; Yan, W.; Xu, J. Study on each phase characteristics of the whole coal life cycle and their ecological risk assessment a case of coal in China. Environ. Sci. Pollut. Res. 2017, 24, 1296-1305. [CrossRef] [PubMed]

31. Peng, J.; Zong, M.; Hu, Y.; Liu, Y.; Wu, J. Assessing landscape ecological risk in a mining city: A case study in Liaoyuan City, China. Sustainability 2015, 7, 8312-8334. [CrossRef]

32. Zhou, S.Y.; Chang, J.; Hu, T.H.; Luo, P.J.; Zhou, H.X. Spatiotemporal Variations of Land Use and Landscape Ecological Risk in a Resource-Based City, from Rapid Development to Recession. Pol. J. Environ. Stud. 2020, 29, 475-490. [CrossRef]

33. Liu, D.; Chen, H.; Zhang, H.; Geng, T.W.; Shi, Q.Q. Spatiotemporal Evolution of Landscape Ecological Risk Based on Geomorphological Regionalization during 1980-2017: A Case Study of Shaanxi Province, China. Sustainability 2020, $12,941$. [CrossRef]

34. Huslshoff, R.M. Landscape indices describing a Dutch landscape. Landsc. Ecol. 1995, 10, 101-111. [CrossRef]

35. Turner, M.G.; Ruscher, C.L. Changes in landscape patterns in Georgia, USA. Landsc. Ecol. 1988, 1, 241-251. [CrossRef]

36. Jin, X.; Jin, Y.X.; Mao, X.F. Ecological risk assessment of cities on the Tibetan Plateau based on land use/land cover changes-Case study of Delingha City. Ecol. Indic. 2019, 101, 185-191. [CrossRef]

37. Zhang, F.; Ayinuer, Y.S.J.; Wang, D.F. Ecological risk assessment due to land use/cover changes (LUCC) in Jinghe County, Xinjiang, China from 1990 to 2014 based on landscape patterns and spatial statistics. Environ. Earth Sci. 2018, 77, 491. [CrossRef]

38. Hua, L.Z.; Liao, J.F.; Chen, H.X.; Chen, D.K. Assessment of ecological risks induced by land use and land cover changes in Xiamen City, China. Int. J. Sustain. Dev. World Ecol. 2018, 25, 439-447. [CrossRef]

39. Klironomos, J.N.; Rillig, M.C.; Allen, M.F. Designing belowground field experiments with the help of semi-variance and power analyses. Appl. Soil Ecol. 1999, 12, 227-238. [CrossRef]

40. Zhang, W.Z.; Yu, J.H.; Wang, D.; Kan, L. Classification and development orientation of resource-based cities. In Study on Sustainable Development of Resource-Based Cities in China; Niu, L., Ed.; Science Press: Beijing, China, 2014; Volume 1, p. 140.

41. Guo, K.; Kuai, X.; Chen, Y.; Qi, L.; Zhang, L.; Liu, Y. Risk assessment of land ecology on a regional scale: Application of the relative risk model to the mining city of Daye, China. Hum. Ecol. Risk Assess. 2017, 23, 550-574. [CrossRef]

42. Pandey, B.; Agrawal, M.; SINGH, S. Ecological risk assessment of soil contamination by trace elements around coal mining area. J. Soils Sediments 2016, 16, 159-168. [CrossRef]

43. Deal, B.; Schunk, D. Spatial dynamic modeling and urban land use transformation: A simulation approach to assessing the costs of urban sprawl. Ecol. Econ. 2004, 51, 79-95. [CrossRef]

44. Zhong, W.J.; Sun, H.Y.; Li, X.J. Research on land utilization change of Feicheng mine area based on ENVI. In Proceedings of the 3rd International Symposium On Modern Mining \& Safety Technology Proceedings, Liaoning Technical University, Fuxin, China, 4 August 2008; pp. 628-632.

45. Li, X.H.; Wang, L.; Li, J.Y. Regional ecological risk assessment in catchment area along the Weihe River based on GIS. Acta Ecol. Sin. 2009, 29, 5523-5534.

46. Areendran, G.; Rao, P.; Raj, K.; Mazumdar, S.; Puri, K. Land use/land cover change dynamics analysis in mining areas of Singrauli district in Madhya Pradesh, India. Trop. Ecol. 2013, 54, 239.

47. Van, M.K.; Jucker, T.; Svenning, J.C. Unifying the concepts of stability and resilience in ecology. J. Ecol. 2021, 03. [CrossRef]

48. Bai, L.M. Evaluation and Optimization of Urban Ecological Resilience in Changchun based on Landscape Pattern. Ph.D. Thesis, Northeast Normal University, Changchun, China, 2019. 
49. Ye, J.; Ma, X.S.; Yang, L. Design and Realization of AHP Toolbox in MATLAB. In Proceedings of the 2008 IEEE International Conference on Granular Computing, Hangzhou, China, 26-28 August 2008; p. 740.

50. Anselin, L.; Getis, A. Spatial statistical analysis and geographic information systems. Ann. Reg. Sci. 1992, 26, 19-33. [CrossRef]

51. Diniz-filho, J.A.F.; Barbosa, A.C.O.F.; Collevatti, R.G.; Chaves, L.J.; Terribile, L.C.; Lima-ribeiro, M.S.; Telles, M.P.C. Spatial autocorrelation analysis and ecological niche modeling allows inference of range dynamics driving the population genetic structure of a Neotropical savanna tree. J. Biogeogr. 2016, 43, 167-177. [CrossRef]

52. Xie, H.L.; Kung, C.C.; Zhao, Y.L. Spatial disparities of regional forest land change based on ESDA and GIS at the county level in Beijing-Tianjin-Hebei area. Front. Earth Sci. 2012, 6, 445-452. [CrossRef]

53. Wang, Y.Q.; Zhao, Y.P.; Bai, Y.R.; Zhang, X. Spatial Heterogeneity of Soil Carbon and its Fractions in the Wolfberry Field of Zhongning County. Huanjing Kexue 2018, 39, 1396-1403. [PubMed]

54. Liu, J.Y.; Zhang, Z.X.; Xu, X.L.; Kuang, W.H.; Zhou, W.C.; Zhang, S.W.; Li, R.D.; Yan, C.Z.; Yu, D.S.; Wu, S.X.; et al. Spatial patterns and driving forces of land use change in China during the early 21st century. J. Geogr. Sci. 2010, 20, 483-494. [CrossRef]

55. Wang, S.Z. Retrospect and Prospect of Shanxi Coal Industry in 70 Year. China Coal Ind. 2020, 1, 14-18. 